\title{
Templated Formation of Luminescent Virus-like Particles by Tailor- Made Pt(II) Amphiphiles
}

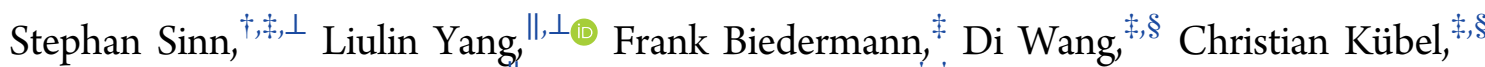 \\ Jeroen J. L. M. Cornelissen, ${ }^{*}, \|_{0}$ and Luisa De Cola ${ }^{*},+\neq(\mathbb{0}$
}

\begin{abstract}
${ }^{\dagger}$ Institut de Science et d’Ingénierie Supramoléculaires (ISIS), Université de Strasbourg \& CNRS, 8 Rue Gaspard Monge, 67000 Strasbourg, France

${ }^{\ddagger}$ Institute of Nanotechnology (INT) and ${ }^{\S}$ Karlsruhe Nano Micro Facility, Karlsruhe Institute of Technology (KIT), Hermann-von-Helmholtz-Platz 1, 76344 Eggenstein-Leopoldshafen, Germany

"Laboratory for Biomolecular Nanotechnology, MESA+ Institute, University of Twente, P.O. Box 207, 7500 AE Enschede, The Netherlands
\end{abstract}

\section{Supporting Information}

ABSTRACT: Virus-like particles (VLPs) have been created from luminescent $\mathrm{Pt}$ (II) complex amphiphiles, able to form supramolecular structures in water solutions, that can be encapsulated or act as templates of cowpea chlorotic mottle virus capsid proteins. By virtue of a bottom-up molecular design, icosahedral and nonicosahedral (rod-like) VLPs have been constructed through diverse pathways, and a relationship between the molecular structure of the complexes and the shape and size of the VLPs has been observed. A deep insight into the mechanism for the templated formation of the differently shaped VLPs was achieved, by electron microscopy measurements (TEM and STEM) and bulk analysis (FPLC, DLS, photophysical investigations). Interestingly, the obtained VLPs can be visualized by their intense emission at room temperature, generated by the self-assembly of the Pt(II) complexes. The encapsulation of the luminescent species is further verified by their higher emission quantum yields inside the VLPs, which is due to the confinement effect of the protein cage. These hybrid materials demonstrate the potential of tailor-made supramolecular systems able to control the assembly of biological building blocks.
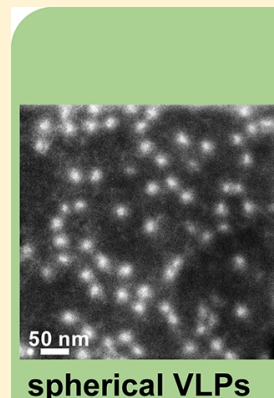

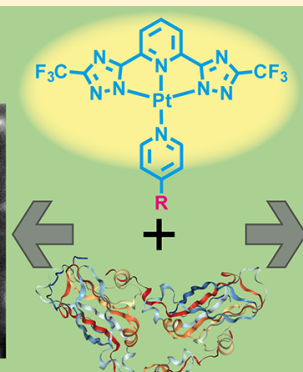

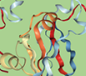

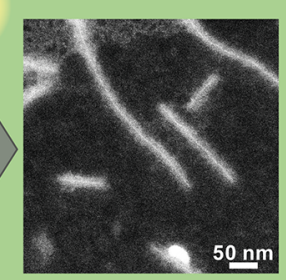

tubular VLPs

\section{INTRODUCTION}

Self-assembly is a powerful tool for the formation of large molecular architectures, able to perform complex functions. ${ }^{1-6}$ An elegant paradigm for the duality of supramolecular morphology and function is represented by the natural virus capsid formation. ${ }^{7-20}$ Natural viral capsid proteins (CPs) have a high preference for forming closed capsids, even in the absence of the naturally templating DNA or RNA. ${ }^{21,22}$ As a representative, cowpea chlorotic mottle virus (CCMV) has been extensively explored as a nanocontainer and nanoreactor, with a wide spectrum of cargos including small molecules, ${ }^{23}$ enzymes, ${ }^{24}$ polymers, ${ }^{25,26}$ micelles, ${ }^{27,28}$ and nanoparticles. ${ }^{29-34}$ For electric neutral cargos, a passive encapsulation can be adopted, resulting in distributions of both filled and empty icosahedral virus-like particles (VLPs) with a triangulation number of $T=3(28 \mathrm{~nm}$ in diameter $)$ structure. ${ }^{27}$ For negatively charged cargos, a templated encapsulation is preferred, resulting in icosahedral VLPs filled by cargos with diverse structures $(T=1,2,3){ }^{23}$ It should be noted that it is not necessary for the CCMV-based VLPs to be icosahedrons. Rigid covalent polymer- or DNA-based scaffolds are capable of triggering the assembly of CPs around the scaffolds, resulting in nonicosahedral VLPs (e.g., rod-like particles). ${ }^{18,35,36}$

In spite of numerous studies of virus-based supramolecular nanostructures, a deep and systematic understanding of pathway complexity of self-assembly, as well as the resulting morphology and functionality, is elusive. ${ }^{37,38}$ Modulation of cooperative and competitive driving forces including templatetemplate interactions, template-protein interactions, and protein-protein interactions is essential to access a better control of self-assembly processes and target functions of VLPs. ${ }^{38,39}$ The template effect is one of the most powerful tools for steering the resulting assembly size and shape. ${ }^{40-43}$ For instance, templates that employ the comparably strong hydrogen-bonding interaction as a directional organization motif are widely utilized in supramolecular chemistry. ${ }^{44,45}$

Taking advantage of a bottom-up molecular design and assembly, it is feasible to establish an ideal integrative system to

Received: December 5, 2017

Published: January 22, 2018 


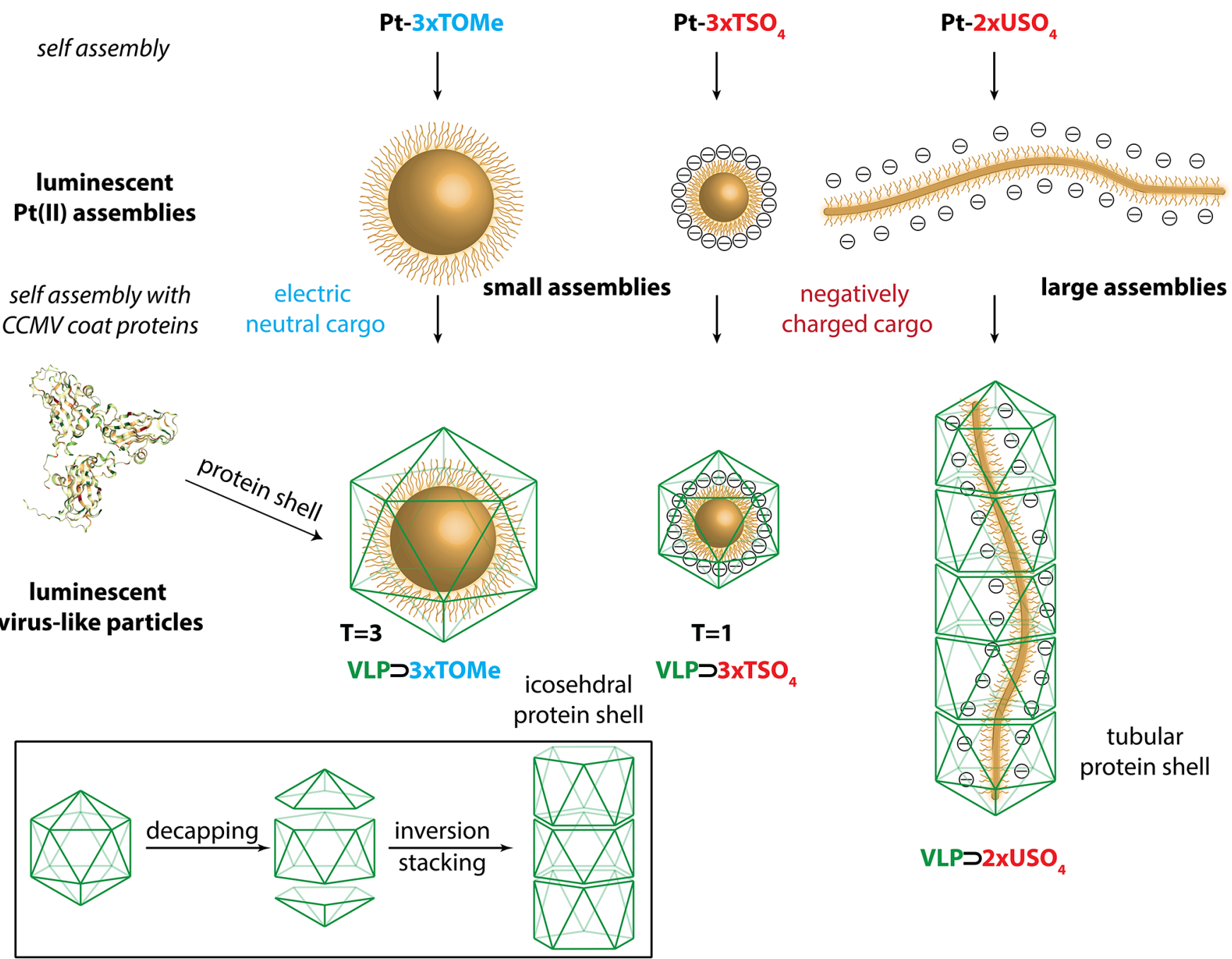

Figure 1. Formation of differently shaped virus-like particles depending on the chosen Pt(II) monomer. The proposed mechanism includes a preceding self-assembly of the $\mathrm{Pt}(\mathrm{II})$ amphiphiles featuring a subsequent self-assembly process with the CCMV coat proteins to spherical (icosahedral) or tubular luminescent virus-like particles. Inset: Schematic formation of tubular structures composed of subunits of "uncapped" icosahedrons.

gain insights into these complex relationships among structure, morphology, and function.

As the size and shape of self-assembled systems often determine the function (e.g., for proteins and DNA), it is of great importance to develop strategies for the control of the molecular assembly process. ${ }^{46}$ In aqueous media, H-bonding and other directional noncovalent bonding motifs (e.g., dipole interactions) are efficiently screened by water as a solvent, ${ }^{47}$ which complicates the design of suitable artificial templates. Moreover, hydrophobic and dispersion interactions are nondirectional and energetically rather weak for small- and medium-sized organic molecules. ${ }^{47-51}$ For instance, the aqueous self-assembly of common synthetic surfactants such as cetyltrimethylammonium bromide (CTAB) or sodium dodecyl sulfate (SDS) into micelles only occurs at greater than millimolar critical aggregation concentration (CAC). ${ }^{52,53}$ In contrast, many biologically relevant systems form much more stable self-assembled structures in water, CAC nanomolar to micromolar for typical biological phospholipids. $^{54,55}$

Recently, we have reported $\mathrm{Pt}(\mathrm{II})$ complexes capable of selfassembling into different emissive nanostructures. ${ }^{56,57}$ Self- aggregation of $\mathrm{Pt}(\mathrm{II})$ complexes is promoted in solution by their square-planar geometry as well as $\pi-\pi$ and hydrophobic interactions of the ligands and at short distances $(<3.5 \AA)$ by $\mathrm{Pt}-\mathrm{Pt}$ interactions. ${ }^{58,59}$ Thus, it is expected that combining a hydrophobic $\mathrm{Pt}$ (II) complex moiety with hydrophilic tails will lead to amphiphiles that form thermodynamically stable selfassembled structures in water.

Here, we demonstrate how assembled amphiphilic platinum complexes can be encapsulated into VLPs or even act as templates to tailor the morphology of VLPs. To achieve our aim, we have synthesized a family of water-soluble platinum complexes which possess a strong emission once they are assembled in solution. The complexes contain a hydrophobic terdentate ligand and a pyridine unit, substituted with tetraethylene glycol or aliphatic chains, as ancillary ligand to complete the coordination sphere of the $\mathrm{Pt}(\mathrm{II})$ ion. We describe how, through subtle modulation of the charge, number, and nature (hydrophobic or hydrophilic) of the tails, we can obtain different morphologies of VLPs. In addition, the luminescence of the assemblies is influenced by the formation and by the morphology of the VLPs. The enhanced photophysical properties of the entrapped $\mathrm{Pt}(\mathrm{II})$ complexes, 
that is, the aggregation-state-dependent emission and the role played by the confinement provided by the assembly of the proteins around the $\mathrm{Pt}$ complexes' supramolecular structures, allow for facile monitoring of the hybrid virus-like particle formation.

\section{RESULTS AND DISCUSSION}

Design, Synthesis, and Characterization of $\mathrm{Pt}(\mathrm{II})$ Complex Amphiphiles. The Pt(II) amphiphiles were based on a square-planar Pt(II) framework comprising a hydrophobic "head", a terdentate ligand (2,6-bis(3-(trifluoromethyl)- $1 \mathrm{H}$ 1,2,4-triazol-5-yl)pyridine), and an ancillary pyridine substituted at position 4 with a hydrophilic moiety based on tetraethylene glycol chains or an alkyl chain. The chain can be neutral or negatively charged when terminated with sulfate units (Scheme 1). These compounds display advantageous

Scheme 1. Pt(II) Complexes Utilized for Encapsulation Experiments Featuring Double or Triple Branched Tetraethylene Glycol (T) or Undecyl (U) Side Chains That Are Terminated by Noncharged Methoxy (-OMe) or Hydroxy $(-\mathrm{OH})$ or by Negatively Charged Sulfate $\left(-\mathrm{SO}_{4}{ }^{-}\right)$ Groups $^{a}$

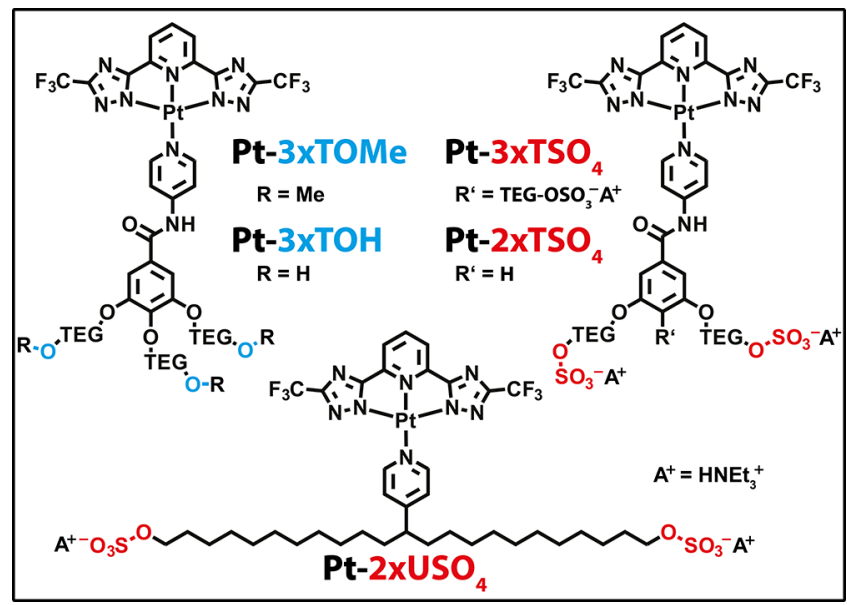

${ }^{a}$ See synthesis section in the SI for synthetic details and other compounds.

photophysical properties over its bis(tetrazole)-Pt(II)-pyridine analogue. ${ }^{.0-62}$ The hydrophilic "tails" were installed on the ancillary ligands through a simple etherification and amidation procedure (see synthesis section in the Supporting Information (SI)) and featured branches (two or three) of tetraethylene glycol that were terminated by $-\mathrm{OMe},-\mathrm{OH}$, or $-\mathrm{OSO}_{3}{ }^{-}$groups (order of increasing hydrophilicity). ${ }^{63,64}$ Furthermore, the $\mathrm{Pt}(\mathrm{II})$ amphiphile with a much larger hydrophobic part (branched undecyl chains) and sulfate end groups, $\mathbf{P t - 2 x U S O}{ }_{4}$, was prepared by a different synthetic route (see synthesis section in the SI). The negatively charged systems were isolated as triethylammonium salts, enabling solubility in aqueous as well as organic media (see Tables S2 and S3 in the SI for details).

These Pt(II) amphiphiles differ from many other commonly used surfactants by their unusual low CAC in the micromolar range $(10-50 \mu \mathrm{M})$ that was determined by dynamic light scattering (DLS) (see Table 1). For comparison, the CAC (or critical micelle concentration (CMC) in the context of micelles) values of sodium cholate $(15 \mathrm{mM})$, SDS $(8 \mathrm{mM})$, CTAB $(0.9 \mathrm{mM})$, and lauryl glucoside $(0.2 \mathrm{mM})$ are $2-3$ orders of magnitude higher than that for the $\mathrm{Pt}(\mathrm{II})$ amphiphiles. The low CAC values are due to an interplay of supramolecular interactions such as hydrophobicity, hydrogen bonds, and $\mathrm{Pt}-\mathrm{Pt}$ and $\pi-\pi$ interactions. Therefore, the assemblies are already formed in aqueous buffer at low concentrations, ensuring their role as the template in the formation of VLPs. From DLS measurements, the hydrodynamic diameter $\left(d_{\text {hyd }}\right)$ of the resulting assemblies formed by the branched tetraethylene glycol based $\mathrm{Pt}(\mathrm{II})$ amphiphiles, such as Pt-3xTOMe, Pt-3xTOH, Pt-3xTSO were in the size range of $d_{\text {hyd }}=5-24 \mathrm{~nm}$ (Table 1 ). The markedly larger size of the noncharged micelles compared to that of analogous negatively charged micelles is in agreement with the observed behavior with different surfactants and the geometric packing model. ${ }^{65}$ These complex aggregates can all fit inside the inner cavity of the icosahedral-shaped CCMV capsid $\left(d_{\text {in }} \approx 21 \mathrm{~nm}\right.$ for $T=3$ particles), as schematically depicted in Figure 1 (see Figure S17 for transmission electron microscopy (TEM) images).

Complex $\mathbf{P t}-2 \mathrm{xUSO}_{4}$ possesses a hydrophobic part much larger than that of the aforementioned amphiphiles (see Scheme 1), balanced by a hydrophilic negatively charged group as the terminal unit. DLS experiments indicated the formation of very large particles $\left(d_{\text {hyd }} \sim 150 \mathrm{~nm}\right)$ upon selfassembly in aqueous buffer, featuring a low CAC of $15 \mu \mathrm{M}$. The TEM images (see Figure S16) show that the pure complex selfassembles in long fibers $(\sim 100-300 \mathrm{~nm})$ featuring a width of around $6 \mathrm{~nm}$. Similar morphologies were reported by Manners

Table 1. Physical and Photophysical Data of the Pt(II) Amphiphiles in TRIS Buffer (pH 7.2)

\begin{tabular}{|c|c|c|c|c|c|}
\hline complex $^{a}$ & $d_{\text {hyd }}(\mathrm{nm})^{b}$ & $\mathrm{CAC}(\mathrm{mM})^{c}$ & $\lambda_{\mathrm{em}}(\mathrm{nm})^{d}$ & $\tau(\mathrm{ns})^{e}$ & $\Phi(\%)^{f}$ \\
\hline Pt-3xTOMe & $24.2 \pm 3.6$ & 0.053 & 600 & $443[367]^{g}$ & $52[36]^{g}$ \\
\hline Pt-3xTOH & $21.9 \pm 3.3$ & 0.024 & 605 & $552[332]^{g}$ & $60[33]^{g}$ \\
\hline $\mathrm{Pt}_{-3 \times \mathrm{TSO}_{4}}$ & $5.6 \pm 1.5$ & 0.018 & 607 & $304[139]^{g}$ & $32[7]^{g}$ \\
\hline Pt-2xTSO 4 & $8.7 \pm 2.2$ & 0.010 & 612 & $171[45]^{g}$ & $14[6]^{g}$ \\
\hline Pt-2xUSO & $150 \pm 21^{h}$ & 0.015 & 578 & $645[586]^{g}$ & $58[22]^{g, i}$ \\
\hline
\end{tabular}

${ }^{a}$ Measurements were performed for $0.1 \mathrm{mM} \mathrm{Pt}(\mathrm{II})$ amphiphile in $50 \mathrm{mM}$ TRIS buffer $(\mathrm{pH} 7.2,10 \mathrm{mM} \mathrm{MgCl})_{2}$ in aerated ambient conditions. See the SI for data at different concentration of amphiphile. ${ }^{b}$ Hydrodynamic diameter determined by DLS. ${ }^{c}$ CAC concentration determined by DLS at fixed angle and attenuation, CAC error $\sim 10 \%$. Note: Appropriately dimensioned particles are necessary for the encapsulation into CCMV capsids. The CAC for the presented $\mathrm{Pt}$ (II) amphiphiles is here understood as the concentration at which the transition from monomers/smaller aggregates (e.g., dimers) to suitably sized aggregates (e.g., micelles) is occurring. ${ }^{d}$ Maximum of emission determined by emission spectroscopy with excitation at $375 \mathrm{~nm}$. ${ }^{e}$ Amplitude weighted average lifetime determined by emission spectroscopy with excitation at $375 \mathrm{~nm} ;$ error $\sim 1 \%$. ${ }^{\text {Emission }}$ quantum yield determined with an integrating sphere; $\varphi$ error $\sim 5 \% .{ }^{g}$ Measurements in square brackets determined at Pt complex concentrations as observed in VLP (see SI). ${ }^{h}$ Size estimation by TEM was performed for nonspherical aggregates (see text). ${ }^{i}$ Determination of $\varphi$ by relative method. 
et al. on analogues $\mathrm{Pt}(\mathrm{II})$ complexes bearing a single extended polyglycol chain $(n=7-16)$ at the ancillary ligand, and long fibers were observed only for the longest chain. ${ }^{66,67}$

The well-known environment- and aggregation-state-dependent emission properties of square-planar $\mathrm{Pt}(\mathrm{II})$ complexes served as a convenient, independent measure for monitoring their self-assembly in aqueous solution. As expected, both the excited-state lifetime and emission quantum yield markedly increase upon formation of aggregated structures above the CAC (Table 1). The formed assemblies possess a strong room temperature emission $(\varphi \sim 14-60 \%)$ featuring an extraordinary long excited-state lifetime (up to $550 \mathrm{~ns}$ ) (see Table 1 and SI for details), in the presence of dioxygen, depending on the molecular structure of the complex. Noteworthy, contrary to common fluorophores, which suffer from aggregation-caused quenching, these platinum(II)-based phosphors render a strong luminescent material at high local and global concentrations due to their aggregation-induced emission properties. Determination of the CAC values through monitoring of the photophysical changes upon dilution of the $\mathrm{Pt}(\mathrm{II})$ amphiphiles in aqueous buffered solution yielded CAC values that well correspond to those obtained by DLS (see Table S4). ${ }^{68}$ However, we noticed that the emission spectra, peaking around $600 \mathrm{~nm}$, always resembled that of the aggregated state of $\mathrm{Pt}(\mathrm{II})$ chromophores even upon strong dilution of the formed assemblies to the nanomolar concentration regime. Usually, a weak blue-shifted emission is observed upon molecular dissolution of $\mathrm{Pt}$ (II) complexes due to the monomeric species unless the $\mathrm{Pt}(\mathrm{II})$ chromophores are covalently tethered together. ${ }^{56}$ Consequently, it appears that the Pt(II) amphiphiles can form remarkably stable assemblies (containing possibly only few units) already much below their CAC, confirming the multiple intermolecular interactions.

Icosahedral VLPs Templated by TEG-Branched Pt(II) Amphiphiles. The good aqueous solubility of the $\mathrm{Pt}(\mathrm{II})$ surfactants and their low critical aggregation concentrations of $10-50 \mu \mathrm{M}$ are important requirements for proper encapsulation experiments with CCMV coat proteins. CP isolation from CCMV was accomplished according to the literature. ${ }^{24,69}$ In general, the preparation of VLPs was conducted as follows. First, the capsid proteins and the $\mathrm{Pt}(\mathrm{II})$ amphiphiles were mixed in a molar ratio of 1:5 in TRIS $\mathrm{pH} 7.2$ buffer. The electrical neutral Pt(II) amphiphiles (Pt-3xTOMe, Pt-3xTOH) decorated with TEG branches cannot induce the assembly of CPs under neutral $\mathrm{pH}$ condition, due to the weak interactions between these amphiphiles and CPs. ${ }^{70}$ Therefore, a passive encapsulation, in which the $\mathrm{pH}$ value was tuned from 7.2 to 5.1, was adopted to achieve the encapsulation (see encapsulation section in the SI for details). The assembly of VLPs is mainly driven by protein-protein interaction under weak acidic conditions. On the other hand, the negatively charged $\mathrm{Pt}(\mathrm{II})$ amphiphiles Pt-3xTSO ${ }_{4}$ and $\mathbf{P t}-\mathbf{2 x T S O} \mathbf{T}_{4}$ underwent encapsulation at $\mathrm{pH} 7.2$ with the $\mathrm{CPs}$, indicating their templating effect. In this case, the assembly of VLPs was driven by the electrostatic interactions between the anionic $\mathrm{Pt}(\mathrm{II})$ amphiphiles and the positively charged CPs and by the proteinprotein interactions.

Subsequently, the samples were purified and characterized by fast protein liquid chromatography (FPLC). The elution volumes around $10.8-11.3 \mathrm{~mL}$ for all samples indicate the formation of VLPs (Figure 2a and SI). A separation of the VLPs from remaining capsid proteins $(17.5 \mathrm{~mL}$ ) and $\mathrm{Pt}(\mathrm{II})$ assemblies was achieved for all samples. The DLS analysis a

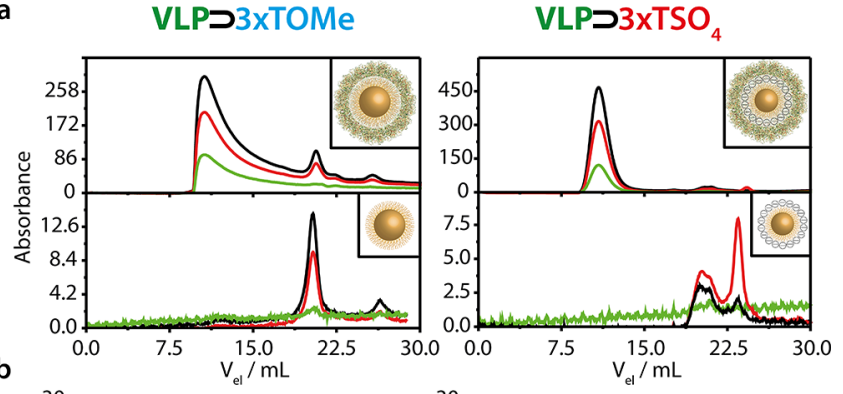

b
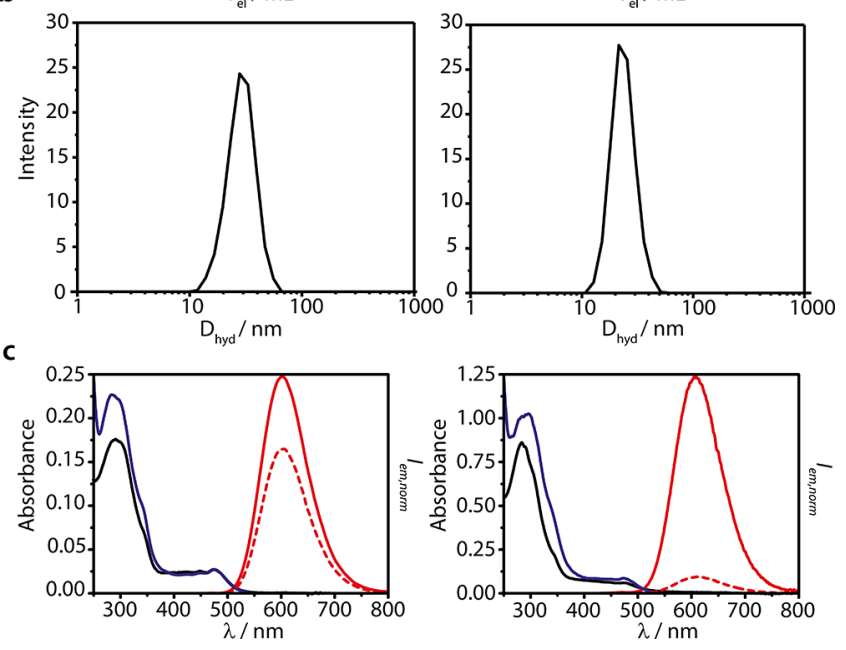

Figure 2. (a) FPLC chromatograms of VLPつ3xTOMe (left) and VLPכ3 $\mathrm{xTSO}_{4}$ (right) and corresponding Pt amphiphile solution without capsid at $1 \mathrm{mM}$ (bottom). Colors indicate absorbance wavelengths: $260 \mathrm{~nm}$ (red), $280 \mathrm{~nm}$ (black), $340 \mathrm{~nm}$ (green). (b) DLS intensity distributions of the VLPつ3xTOMe (left) and VLPつ3xTSO (right). (c) Absorption spectra (solid, black), excitation (solid, blue, $\lambda_{\mathrm{em}}=\lambda_{\mathrm{em}, \max ,}$ arbitrary units), and emission (solid, red, $\lambda_{\mathrm{exc}}=405 \mathrm{~nm}$, normalized) spectra of the VLPs VLPכ3xTOMe (left) and VLP $\supset 3 \mathrm{xSO}_{4}$ (right). The quantum yield weighted emission spectra (dashed, red, $\lambda_{\text {exc }}=405 \mathrm{~nm}$ ) of the corresponding Pt amphiphiles (Pt-

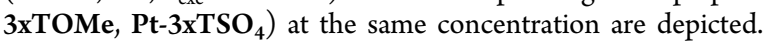

(Figure $2 \mathrm{~b}$ and SI) confirms the formation of VLPs with $d_{\text {hyd }}$ of $\sim 28 \mathrm{~nm}$ for VLPつ3xTOMe and VLPつ3xTOH and $d_{\text {hyd }}$ of

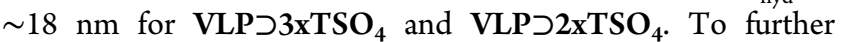
confirm the estimated results from FPLC and DLS, TEM experiments were performed with uranyl acetate staining. Spherical particles were observed for VLPつ3xTOMe and VLPつ3xTOH, with a diameter of $\sim 28 \mathrm{~nm}$; also, spherical

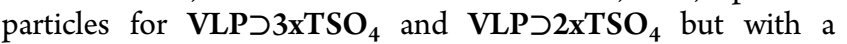
diameter of $\sim 18 \mathrm{~nm}$. The results are consistent with the DLS results (Figure $3 \mathrm{a}$ and $\mathrm{SI}$ ).

The TEM images show that the filled particles display a spherical shape and an entirely bright contrast, whereas less filled cages appear with a dark contrast in the interior, resembling donuts. While predominantly filled VLPs were observed for the encapsulation with negative $\mathrm{Pt}(\mathrm{II})$ assemblies, the neutral analogues resulted in distributions of filled and empty VLPs. This behavior is in agreement with the different capsid formation mechanism, templated versus statistical by $\mathrm{pH}$ changes, for negatively charged and noncharged cargos, respectively. High-angle annular dark-field scanning transmission electron microscopy (HAADF-STEM, no staining) analysis reveals a high average atomic number $(Z)$ due to the heavy $\mathrm{Pt}$ atoms, shown as bright spots within the dark outer low $Z$ protein shell (Figure 3c). Accumulated energy-dispersive 

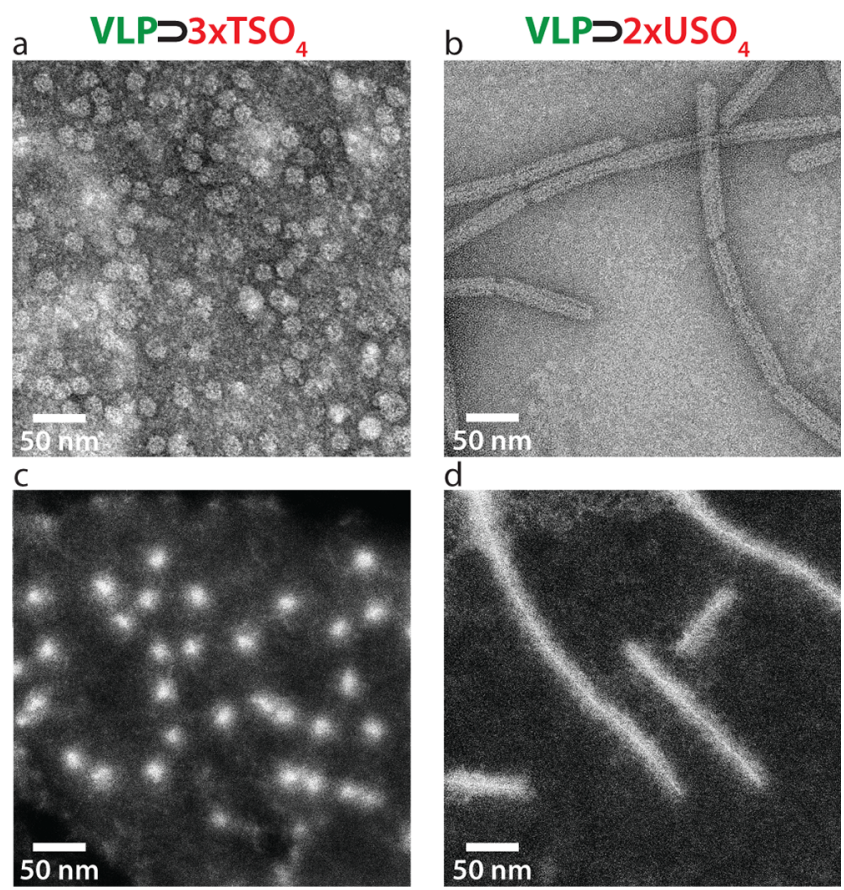

Figure 3. (a) TEM (negative stain) image of VLPכ3xTSO (negative stain) image of VLPつ2 $\mathbf{x U S O}_{4}$. (c) HAADF-STEM (no staining) image of VLPכ3xTSO ${ }_{4}$. (d) HAADF-STEM (no staining) image of VLP $\supset 2 \mathbf{x U S O}_{4}$. The scale bars are $50 \mathrm{~nm}$.

X-ray spectroscopy of a set of particles also displayed characteristic platinum signals (SI).

The average loading of the $\mathrm{Pt}(\mathrm{II})$ complex per capsid was estimated from inductively coupled plasma mass spectrometry (ICP-MS) measurements. Approximately 8-20 negatively charged Pt-3xTSO ${ }_{4}$ and $\mathbf{P t - 2} \mathrm{xTSO}_{4}$ amphiphiles were encapsulated into one virus capsid, resulting in a high local concentration of 40-100 mM (Table 2), when assuming an inner diameter of $8.5 \mathrm{~nm}$ for the nearly spherical icosahedral $T$ $=1$ capsid $\left(V \approx 321 \mathrm{~nm}^{3}\right)$. The concentration enrichment by a factor of $130-310$ of the $\mathrm{Pt}$ (II) cargo due to the templating effect is evident. The average occupation for noncharged amphiphiles was much lower (average was 1-4 per virus capsid), pointing also to a mixture of filled and empty capsids.

Table 2. Physical and Photophysical Data of the Pt(II) Amphiphiles in TRIS Buffer (pH 7.2) ${ }^{a}$

\begin{tabular}{|c|c|c|c|c|c|}
\hline VLP & $d_{\text {hyd }}(\mathrm{nm})^{b}$ & $\begin{array}{l}c_{\text {Pt,local }} \\
(\mathrm{mM})^{c}\end{array}$ & $\underset{(\mathrm{nm})^{d}}{\lambda_{\mathrm{em}}}$ & $\tau(\mathrm{ns})^{e}$ & $\Phi(\%)^{\prime}$ \\
\hline VLPつ3xTOMe & $29.6 \pm 1.5$ & 0.28 & 601 & 474 & 51 \\
\hline VLPつ3xTOH & $28.7 \pm 1.4$ & 1.46 & 605 & $502^{g}$ & 54 \\
\hline VLP $\supset 3 x T_{S O} O_{4}$ & $18.1 \pm 0.5$ & 102.49 & 607 & 612 & 57 \\
\hline VLP $\supset 2 \mathrm{xTSO}_{4}$ & $19.5 \pm 1.6$ & 43.19 & 604 & 620 & 52 \\
\hline VLP $\supset 2 \mathrm{xUSO}_{4}$ & $>50[\sim 18]^{g}$ & 5.86 & 600 & 462 & 23 \\
\hline
\end{tabular}

${ }^{a}$ Measurements were performed with the solution isolated from FPLC (see Figure 2a). ${ }^{b}$ Hydrodynamic diameter determined by DLS. ${ }^{c}$ Local $\mathrm{Pt}$ (II) complex concentration calculated from ICP-MS (AES) data for $\mathrm{Pt}$ and $\mathrm{S}$. ${ }^{d}$ Maximum of emission determined by emission spectroscopy with excitation at $375 \mathrm{~nm}$. ${ }^{e}$ Amplitude weighted average lifetime determined by emission spectroscopy with excitation at $375 \mathrm{~nm} ; \tau$ error $\sim 1 \% .{ }^{f}$ Emission quantum yield determined with an integrating sphere; $\varphi$ error $\sim 5 \% .{ }^{g}$ Size estimation by TEM was performed for nonspherical particles (see text) for the length and width (displayed in square brackets).
In particular, upon encapsulation, $\mathrm{Pt}(\mathrm{II})$ concentration enrichment for Pt-3xTOMe was very little and only of a factor 4 for Pt-3xTOH (see Table 2). The results are in agreement with a passive encapsulation mechanism. The obtained VLPs with either neutral or negative $\mathrm{Pt}(\mathrm{II})$ assemblies entrapped inside display a strong room temperature emission around $600 \mathrm{~nm}$, long emission lifetimes (474-620 ns), and high quantum yields $(51-57 \%)$ (see Figure 2c, Table 2, and SI), remaining unaffected by dilution or the presence of dioxygen (see photophysical analysis of VLPs in the SI for deaeration experiments). In fact, the photophysical properties of the noncharged $\mathrm{Pt}(\mathrm{II})$-amphiphile-filled capsids resemble that of the self-assembled $\mathrm{Pt}$ (II) amphiphiles at high concentrations in aqueous buffer, although the bulk concentrations of $\mathrm{Pt}(\mathrm{II})$ amphiphiles are much lower than their CAC (SI, Table S1).

The observed photophysical parameters, such as a strong metal/metal-to-ligand charge transfer absorption band at 475 $\mathrm{nm}$ and the broad emission profiles peaking around $600 \mathrm{~nm}$, are indicative of $\mathrm{Pt}-\mathrm{Pt}$ interactions and thus aggregation of the $\mathrm{Pt}(\mathrm{II})$ complexes. $^{60,71-73}$ These results suggest that the $\mathrm{Pt}(\mathrm{II})$ amphiphile species are present at a high local concentration inside the filled virus capsids. The negatively charged VLPs reveal a strong enhancement of their emission quantum yield upon encapsulation into the virus capsids (factor up to 13), leveling off at the maximum values observed for the noncharged $\mathrm{Pt}$ (II) amphiphiles and other aqueous self-assembling $\mathrm{Pt}$ (II) complexes based on the same terdentate $\mathrm{N}$-metallacycling ligand. ${ }^{60}$ This increase in quantum yield of the negatively charged amphiphiles upon virus encapsulation may be due to the high local concentration inside the capsids, ${ }^{23}$ which prevents motions of the luminophores, leading to rigidochromic effects. ${ }^{74}$ The enhanced rigidity by the immobilization of the negatively charged tail in the positively charged protein shell leads most likely to a decrease in the nonradiative deactivation pathways. ${ }^{75,76}$

Rod-like VLPs Templated by Alkyl-Branched Pt(II) Amphiphiles. Unlike many soft artificial self-assembling systems, CCMV capsid formation is expected to show little propensity for change in shape and size, as this would potentially impact its biological function. The successful entrapment of assemblies constituted by tetraethylene glycol based $\mathrm{Pt}$ (II) complexes showed, however, that the morphology of the VLPs is not modified by the loaded species. Indeed, in all cases, a natively shaped icosahedral virus cage was maintained. It turns out that when the size of templates is comparable to or smaller than the inner space of the icosahedral protein cage $(\sim 21 \mathrm{~nm})$, the protein-protein interaction promotes the assembly of CPs into icosahedron particles $(T=1,2,3)$ preferentially. In other words, the high shape persistence of the CCMV capsid formation overpowers the geometric preference of the amphiphile templates. We demonstrate that, through the use of a robust supramolecular template with a large size and a high aspect ratio, the template-protein interactions may force the assembly of CPs to accommodate the preferred shape of the template, resulting in VLPs with tailored nonicosahedron morphology.

To this end, the chemical structure of the $\mathrm{Pt}(\mathrm{II})$ amphiphiles was modified such that thermodynamic stable rod-like supramolecular structures were formed by the amphiphiles. Albeit overlooked by the classic packing model, the transition from spherical to extended rod-like assemblies can be triggered when the chain length or solvatophobic nature of a surfactant tail is modified. ${ }^{65}$ We utilized this feature by exchanging the 
tetraethylene glycol chains with more hydrophobic alkyl chains (undecyl), retaining the negatively charged, hydrophilic and virus-protein attracting head groups, and the $\mathrm{Pt}(\mathrm{II})$ complex core. The chemical structure of the obtained Pt-2xUSO amphiphile is shown in Scheme 1 (see the SI for synthetic procedure). Indeed, self-assembly of $\mathbf{P t}-2 \mathrm{xUSO}_{4}$ in aqueous media leads to the appearance of long $(>50 \mathrm{~nm})$ and thin $(\sim 6$ $\mathrm{nm}$ ) rods (see Figure S14). Their low CAC value and their characteristic photophysical properties were in accordance with a thermodynamically stable, closely packed self-aggregated structure, suggesting that these may be appropriate supramolecular templates that could induce the formation of rod-like VLPs.

As expected, mixing CPs $(0.066 \mathrm{mM})$ and $\mathbf{P t}-\mathbf{2} \mathbf{x U S O}_{4}$ amphiphiles $(0.33 \mathrm{mM})$ resulted in the formation of rod-like assemblies (see encapsulation section in the SI for details). The TEM images of the resultant VLPs display predominantly cylindrical (nonicosahedral) rods (Figure 3b,d). The obtained rod-like VLPs vary in their length $(100-500 \mathrm{~nm})$ but possess a homogeneous thickness around $18 \mathrm{~nm}$, which is comparable to the diameter of a protein icosahedron with $T=1$ but larger than that of the self-assembled $\mathbf{P t}$-2xUSO $\mathbf{S O}_{4}$ fibers $(6 \mathrm{~nm}){ }^{77}$ The apparent enlarged cross section diameter suggested the formation of a protein shell around the $\mathrm{Pt}$ (II) complex threads. HAADF-STEM analysis displays a high average atomic number $(Z)$ due to the heavy Pt atoms as bright lines within the dark outer low $Z$ protein shell (Figure $3 \mathrm{~d}$ ), confirming the presence of $\mathrm{Pt}(\mathrm{II})$ inside the shell.

The obtained VLPs show room temperature emission peaking at $600 \mathrm{~nm}$ with a quantum yield of $23 \%$ and an excited-state lifetime of 462 ns, which are typical features for the assembled $\mathrm{Pt}$ (II) complexes (see photophysical analysis of VLPs in SI for details). These fibrous VLPs contained a local, concentration-enriched $\mathrm{Pt}$ (II) complex content similar to that of the virus capsids that were templated by negatively charged TEG-branched Pt(II) amphiphiles (Table 2).

The mechanism of the formation of rod-like VLPs is not well understood. ${ }^{12}$ On the basis of the established quasi-equivalence model of Casper and Klug, ${ }^{22}$ one can understand the observed spherical particles as an icosahedral organized protein shell with a triangulation of $T=1$ (Figure 1). All negative cargos increase the local concentration of protein dimers that facilitate the formation of pentamers-of-dimers. ${ }^{19}$ In contrast to the smaller negative assemblies $\left(d_{\text {hyd }}<\right.$ inner CCMV diameter), the larger cargo, based on Pt-2xUSO ${ }_{4}$ ( $d_{\text {hyd }}>$ inner CCMV diameter), perturbs the curvature for the formation of icosahedral $T=1$ particles (Figure 1). The misalignment of pentamers avoids the closure to a spherical (icosahedral) particle, leading to elongated subunits that allow for rod-like structures via protein-protein interactions. The VLPs therefore can grow long while retaining their thickness. While our findings and explanations are in agreement with the observation and theories of other groups, ${ }^{77,78}$ further experiments are ongoing in our laboratories to confirm the proposed mechanism.

\section{CONCLUSION}

Water-soluble Pt(II) amphiphiles decorated with tetraethylene glycol branches and sulfate groups were synthesized and probed for their self-assembly properties. The luminescent $\mathrm{Pt}(\mathrm{II})$ complexes are soluble in organic and aqueous buffered solution. In buffered solution, intense room temperature emission was observed also at low concentrations because of the selfassembly of the $\mathrm{Pt}(\mathrm{II})$ complexes. The assemblies have been used to template CCMV proteins, yielding luminescent viruslike particles. A remarkable enhancement of the photophysical properties was observed for the negatively charged amphiphiles, rendering a VLP quantum yield of $57 \%$. We gained a deep understanding of correlations among molecular structure, supramolecular architecture, and on the formation of VLPs. Taking advantage of the modulation of multiple interactions between templates and capsid proteins through the molecular design, it is possible to manage the self-assembly process resulting in tailored morphology of VLPs as well as functionality. The negatively charged platinum compounds induced a templated formation of VLPs, which can be icosahedral or nonicosahedral (rod-like) depending on the molecular structure of amphiphilic templates. To the best of our knowledge, this is the first example where a supramolecular material (self-assembled $\mathrm{Pt}(\mathrm{II})$ complexes) induces a shape change in the CCMV capsid formation. We envisage that different supramolecular templates can lead to a variety of shapes and stabilities of VLPs, which in turn can have a strong impact in biomedical applications.

\section{ASSOCIATED CONTENT}

\section{S Supporting Information}

The Supporting Information is available free of charge on the ACS Publications website at DOI: $10.1021 /$ jacs.7b12447.

Experimental details, further chemical characterization and photophysical analysis, additional figures and table (PDF)

\section{AUTHOR INFORMATION}

\section{Corresponding Authors}

*j.j.l.m.cornelissen@utwente.nl

*decola@unistra.fr

ORCID $\odot$

Liulin Yang: 0000-0003-3342-8137

Jeroen J. L. M. Cornelissen: 0000-0002-9728-5043

Luisa De Cola: 0000-0002-2152-6517

\section{Author Contributions}

${ }^{\perp}$ S.S. and L.Y. contributed equally.

\section{Notes}

The authors declare no competing financial interest.

\section{ACKNOWLEDGMENTS}

L.D.C. and S.S. are grateful for the financial support by the University of Strasbourg, the European Research Council, ERC Advanced Grant (Grant Agreement No. 2009-247365). S.S. and F.B. thank the DFG Emmy Noether program (BI 1805/21) for financial support. J.J.L.M.C. and L.Y. thank the European Research Council for financial support by a Consolidator Grant ProtCage (616907 to J.J.L.M.C.). We thank Piotr Paluch for some help of sample preparation and characterization. Rico Keim and Pablo Castro-Hartmann are gratefully acknowledged for their help with TEM analysis. Leana Travaglini, Simone Silvestrini, and Eko Prasetyanto are gratefully acknowledged for their help with material characterization. Naveen Alampally and Christian Strassert are kindly acknowledged for their scientific support.

\section{REFERENCES}

(1) Aida, T.; Meijer, E. W.; Stupp, S. I. Science 2012, 335 (6070), 813-817. 
(2) Whitesides, G. M.; Mathias, J. P.; Seto, C. T. Science 1991, 254 (5036), 1312.

(3) Whitesides, G. M.; Grzybowski, B. Science 2002, 295, 2418-2421.

(4) Lehn, J. M. Science 2002, 295 (5564), 2400-3.

(5) Whitesides, G. M.; Boncheva, M. Proc. Natl. Acad. Sci. U. S. A. 2002, 99 (8), 4769-4774.

(6) Reinhoudt, D. N.; Crego-Calama, M. Science 2002, 295, 24032407.

(7) Adolph, K. W.; Butler, P. J. G. J. Mol. Biol. 1974, 88 (2), 327341.

(8) Douglas, T.; Dickson, D. P. E.; Betteridge, S.; Charnock, J.; Garner, C. D.; Mann, S. Science 1995, 269, 54-57.

(9) Douglas, T.; Young, M. Nature 1998, 393 (6681), 152-155.

(10) Zlotnick, A. J. Mol. Biol. 1994, 241 (1), 59-67.

(11) Liepold, L. O.; Revis, J.; Allen, M.; Oltrogge, L.; Young, M.; Douglas, T. Phys. Biol. 2005, 2 (4), S166.

(12) Lavelle, L.; Gingery, M.; Phillips, M.; Gelbart, W. M.; Knobler, C. M.; Cadena-Nava, R. D.; Vega-Acosta, J. R.; Pinedo-Torres, L. A.; Ruiz-Garcia, J. J. Phys. Chem. B 2009, 113 (12), 3813-3819.

(13) Putri, R. M.; Cornelissen, J. J. L. M.; Koay, M. S. T. ChemPhysChem 2015, 16 (5), 911-918.

(14) Minten, I. J.; Hendriks, L. J. A.; Nolte, R. J. M.; Cornelissen, J. J. L. M. J. Am. Chem. Soc. 2009, 131 (49), 17771-17773.

(15) Millán, J. G.; Brasch, M.; Anaya-Plaza, E.; de la Escosura, A.; Velders, A. H.; Reinhoudt, D. N.; Torres, T.; Koay, M. S. T.; Cornelissen, J. J. L. M. J. Inorg. Biochem. 2014, 136, 140-146.

(16) Lavelle, L.; Michel, J.-P.; Gingery, M. J. Virol. Methods 2007, 146 (1-2), 311-316.

(17) Ochoa, W. F.; Chatterji, A.; Lin, T.; Johnson, J. E. Chem. Biol. 2006, 13 (7), 771-778.

(18) Mukherjee, S.; Pfeifer, C. M.; Johnson, J. M.; Liu, J.; Zlotnick, A. J. Am. Chem. Soc. 2006, 128 (8), 2538-2539.

(19) Tang, J.; Johnson, J. M.; Dryden, K. A.; Young, M. J.; Zlotnick, A.; Johnson, J. E. J. Struct. Biol. 2006, 154 (1), 59-67.

(20) Brumfield, S.; Willits, D.; Tang, L.; Johnson, J. E.; Douglas, T.; Young, M. J. Gen. Virol. 2004, 85, 1049-1053.

(21) Goldberg, M. Tohoku Math. J. 1937, 43, 104-108.

(22) Caspar, D. L.; Klug, A. Cold Spring Harbor Symp. Quant. Biol. 1962, 27, 1-24

(23) Brasch, M.; de la Escosura, A.; Ma, Y.; Uetrecht, C.; Heck, A. J. R.; Torres, T.; Cornelissen, J. J. L. M. J. Am. Chem. Soc. 2011, 133 (18), 6878-6881.

(24) Comellas-Aragones, M.; Engelkamp, H.; Claessen, V. I.; Sommerdijk, N. A.; Rowan, A. E.; Christianen, P. C.; Maan, J. C.; Verduin, B. J.; Cornelissen, J. J.; Nolte, R. J. Nat. Nanotechnol. 2007, 2 (10), 635-9.

(25) Comellas-Aragonès, M.; de la Escosura, A.; Dirks, A. J.; van der Ham, A.; Fusté-Cuñé, A.; Cornelissen, J. J. L. M.; Nolte, R. J. M. Biomacromolecules 2009, 10 (11), 3141-3147.

(26) Sikkema, F. D.; Comellas-Aragones, M.; Fokkink, R. G.; Verduin, B. J. M.; Cornelissen, J. J. L. M.; Nolte, R. J. M. Org. Biomol. Chem. 2007, 5 (1), 54-57.

(27) Kwak, M.; Minten, I. J.; Anaya, D.-M.; Musser, A. J.; Brasch, M.; Nolte, R. J. M.; Müllen, K.; Cornelissen, J. J. L. M.; Herrmann, A. J. Am. Chem. Soc. 2010, 132 (23), 7834-7835.

(28) Chang, C. B.; Knobler, C. M.; Gelbart, W. M.; Mason, T. G. ACS Nano 2008, 2 (2), 281-286.

(29) Dragnea, B.; Chen, C.; Kwak, E.-S.; Stein, B.; Kao, C. C. J. Am. Chem. Soc. 2003, 125 (21), 6374-6375.

(30) Chen, C.; Daniel, M.-C.; Quinkert, Z. T.; De, M.; Stein, B.; Bowman, V. D.; Chipman, P. R.; Rotello, V. M.; Kao, C. C.; Dragnea, B. Nano Lett. 2006, 6 (4), 611-615.

(31) Dixit, S. K.; Goicochea, N. L.; Daniel, M.-C.; Murali, A.; Bronstein, L.; De, M.; Stein, B.; Rotello, V. M.; Kao, C. C.; Dragnea, B. Nano Lett. 2006, 6 (9), 1993-1999.

(32) Bronstein, L. M. Small 2011, 7 (12), 1609-1618.

(33) Liu, A.; Traulsen, C. H. H.; Cornelissen, J. J. L. M. ACS Catal. 2016, 6 (5), 3084-3091.
(34) Liu, A.; Verwegen, M.; de Ruiter, M. V.; Maassen, S. J.; Traulsen, C. H. H.; Cornelissen, J. J. L. M. J. Phys. Chem. B 2016, 120 (26), 6352-6357.

(35) de la Escosura, A.; Janssen, P. G. A.; Schenning, A. P. H. J.; Nolte, R. J. M.; Cornelissen, J. J. L. M. Angew. Chem., Int. Ed. 2010, 49 (31), 5335-5338.

(36) Ng, B. C.; Chan, S. T.; Lin, J.; Tolbert, S. H. ACS Nano 2011, 5 (10), 7730-7738.

(37) Liu, Z.; Qiao, J.; Niu, Z.; Wang, Q. Chem. Soc. Rev. 2012, 41 (18), 6178-6194.

(38) Wen, A. M.; Steinmetz, N. F. Chem. Soc. Rev. 2016, 45 (15), 4074-4126.

(39) Yang, L.; Liu, A.; Cao, S.; Putri, R. M.; Jonkheijm, P.; Cornelissen, J. J. L. M. Chem. - Eur. J. 2016, 22 (44), 15570-15582.

(40) Steed, J. W.; Atwood, J. L. Supramolecular Chemistry; WileyVCH: Weinheim, Germany, 2009.

(41) Bibal, B.; Mongin, C.; Bassani, D. M. Chem. Soc. Rev. 2014, 43 (12), 4179-4198.

(42) Ayme, J.-F.; Beves, J. E.; Leigh, D. A.; McBurney, R. T.; Rissanen, K.; Schultz, D. Nat. Chem. 2012, 4 (1), 15-20.

(43) Wörsdörfer, B.; Woycechowsky, K. J.; Hilvert, D. Science 2011, 331 (6017), 589.

(44) Yu, C.; Mosbach, K. J. Org. Chem. 1997, 62 (12), 4057-4064.

(45) Prins, L. J.; Reinhoudt, D. N.; Timmerman, P. Angew. Chem., Int. Ed. 2001, 40 (13), 2382-2426.

(46) Sasaki, E.; Böhringer, D.; van de Waterbeemd, M.; Leibundgut, M.; Zschoche, R.; Heck, A. J. R.; Ban, N.; Hilvert, D. Nat. Commun. 2017, 8, 14663.

(47) Biedermann, F.; Schneider, H.-J. Chem. Rev. 2016, 116 (9), $5216-5300$

(48) Chandler, D. Nature 2005, 437 (7059), 640-7.

(49) Li, I. T. S.; Walker, G. C. Acc. Chem. Res. 2012, 45 (11), 20112021.

(50) Schneider, H.-J. Acc. Chem. Res. 2015, 48 (7), 1815-1822.

(51) Wagner, J. P.; Schreiner, P. R. Angew. Chem., Int. Ed. 2015, 54 (42), 12274-12296.

(52) Fuguet, E.; Ràfols, C.; Rosés, M.; Bosch, E. Anal. Chim. Acta 2005, $548(1-2), 95-100$.

(53) Techen, A.; Hille, C.; Dosche, C.; Kumke, M. U. J. Colloid Interface Sci. 2012, 377 (1), 251-261.

(54) Marsh, D. Handbook of Lipid Bilayers; CRC Press: Boca Raton, FL, 2013.

(55) Avanti Polar Lipids Inc.: Critical Micelle Concentrations (CMCs); https://avantilipids.com/tech-support/physical-properties/ cmcs/ (accessed March 20, 2017).

(56) Sinn, S.; Biedermann, F.; Vishe, M.; Aliprandi, A.; Besnard, C.; Lacour, J.; De Cola, L. ChemPhysChem 2016, 17 (12), 1829-34.

(57) El Garah, M.; Sinn, S.; Dianat, A.; Santana-Bonilla, A.; Gutierrez, R.; De Cola, L.; Cuniberti, G.; Ciesielski, A.; Samori, P. Chem. Commun. (Cambridge, U. K.) 2016, 52 (74), 11163-6.

(58) Aliprandi, A.; Mauro, M.; De Cola, L. Nat. Chem. 2016, 8 (1), $10-5$.

(59) Liptrot, D. J.; Power, P. P. Nature Reviews Chemistry 2017, 1, 0004.

(60) Sinn, S.; Biedermann, F.; De Cola, L. Chem. - Eur. J. 2017, 23 (8), 1965-1971.

(61) Allampally, N. K.; Bredol, M.; Strassert, C. A.; De Cola, L. Chem. - Eur. J. 2014, 20 (51), 16863-16868.

(62) Mauro, M.; Aliprandi, A.; Cebrian, C.; Wang, D.; Kubel, C.; De Cola, L. Chem. Commun. 2014, 50 (55), 7269-7272.

(63) Müller, M. K.; Brunsveld, L. Angew. Chem., Int. Ed. 2009, 48 (16), 2921-2924.

(64) Kim, B. R.; Lee, H.-G.; Kang, S.-B.; Sung, G. H.; Kim, J.-J.; Park, J. K.; Lee, S.-G.; Yoon, Y.-J. Synthesis 2012, 44 (01), 42-50.

(65) Nagarajan, R. Langmuir 2002, 18 (1), 31-38.

(66) Robinson, M. E.; Nazemi, A.; Lunn, D. J.; Hayward, D. W.; Boott, C. E.; Hsiao, M.-S.; Harniman, R. L.; Davis, S. A.; Whittell, G. R.; Richardson, R. M.; De Cola, L.; Manners, I. ACS Nano 2017, 11 (9), 9162-9175. 
(67) Robinson, M. E.; Lunn, D. J.; Nazemi, A.; Whittell, G. R.; De Cola, L.; Manners, I. Chem. Commun. 2015, 51 (88), 15921-15924.

(68) Biedermann, F. Self-Assembly in Aqueous Media. Comprehensive Supramolecular Chemistry II; Elsevier: Oxford, 2017; pp 241-268.

(69) Verduin, B. J. M. FEBS Lett. 1974, 45 (1), 50-54.

(70) Sun, J.; DuFort, C.; Daniel, M.-C.; Murali, A.; Chen, C.; Gopinath, K.; Stein, B.; De, M.; Rotello, V. M.; Holzenburg, A.; Kao, C. C.; Dragnea, B. Proc. Natl. Acad. Sci. U. S. A. 2007, 104 (4), 13541359.

(71) Septiadi, D.; Aliprandi, A.; Mauro, M.; De Cola, L. RSC Adv. 2014, 4 (49), 25709-25718.

(72) Miskowski, V. M.; Houlding, V. H. Inorg. Chem. 1989, 28 (8), $1529-1533$.

(73) Ma, B.; Li, J.; Djurovich, P. I.; Yousufuddin, M.; Bau, R.; Thompson, M. E. J. Am. Chem. Soc. 2005, 127 (1), 28-29.

(74) Genovese, D.; Aliprandi, A.; Prasetyanto, E. A.; Mauro, M.; Hirtz, M.; Fuchs, H.; Fujita, Y.; Uji-I, H.; Lebedkin, S.; Kappes, M.; De Cola, L. Adv. Funct. Mater. 2016, 26 (29), 5271-5278.

(75) Kubicki, J.; Maciejewski, A.; Milewski, M.; Wrozowa, T.; Steer, R. P. Phys. Chem. Chem. Phys. 2002, 4 (2), 173-179.

(76) Dsouza, R. N.; Pischel, U.; Nau, W. M. Chem. Rev. 2011, 111 (12), 7941-7980.

(77) Prasad, B. V.; Schmid, M. F. Advances in experimental medicine and biology 2012, 726, 17-47.

(78) Bancroft, J. B.; Hills, G. J.; Markham, R. Virology 1967, 31 (2), 354-379. 